\title{
VIAGENS PELO SUL EM TRÊS TEMPOS
}

\author{
Jonas Kunzler Moreira Dornelles
}

Submetido em 15 de abril de 2019.

Aceito para publicação em 24 de julho de 2019.

Cadernos do IL, Porto Alegre, n. ${ }^{\circ}$ 58, outubro. p. 150-162.

\section{POLÍTICA DE DIREITO AUTORAL}

Autores que publicam nesta revista concordam com os seguintes termos:

(a) Os autores mantêm os direitos autorais e concedem à revista o direito de primeira publicação, com o trabalho simultaneamente licenciado sob a Creative Commons Attribution License, permitindo o compartilhamento do trabalho com reconhecimento da autoria do trabalho e publicação inicial nesta revista.

(b) Os autores têm autorização para assumir contratos adicionais separadamente, para distribuição não exclusiva da versão do trabalho publicada nesta revista (ex.: publicar em repositório institucional ou como capítulo de livro), com reconhecimento de autoria e publicação inicial nesta revista.

(c) Os autores têm permissão e são estimulados a publicar e distribuir seu trabalho online (ex.: em repositórios institucionais ou na sua página pessoal) a qualquer ponto antes ou durante o processo editorial, já que isso pode gerar alterações produtivas, bem como aumentar o impacto e a citação do trabalho publicado.

(d) Os autores estão conscientes de que a revista não se responsabiliza pela solicitação ou pelo pagamento de direitos autorais referentes às imagens incorporadas ao artigo. A obtenção de autorização para a publicação de imagens, de autoria do próprio autor do artigo ou de terceiros, é de responsabilidade do autor. Por esta razão, para todos os artigos que contenham imagens, o autor deve ter uma autorização do uso da imagem, sem qualquer ônus financeiro para os Cadernos do IL.

\section{POLÍTICA DE ACESSO LIVRE}

Esta revista oferece acesso livre imediato ao seu conteúdo, seguindo o princípio de que disponibilizar gratuitamente o conhecimento científico ao público proporciona sua democratização.

http://seer.ufrgs.br/cadernosdoil/index

Segunda-feira, 07 de outubro de 2019. 


\title{
VIAGENS PELO SUL EM TRÊS TEMPOS
}

\section{SOUTH BRAZILIAN TRAVELS IN THREE TIMES}

\author{
Jonas Kunzler Moreira Dornelles*
}

\begin{abstract}
RESUMO: A literatura do Rio Grande do Sul possui, desde suas origens, exemplos de obras em que a viagem e o deslocamento são mobilizadores da narrativa. No início, o desejo do autor de retratar a "cor local" aproximou as ficções regionais do registro pitoresco e dos costumes. Essa tradição algo romântica sofrerá um abalo a partir dos elementos naturalistas em Alcides Maya, que mostrará um Sul em vias de extinção. Cyro Martins continuará esse processo, descrevendo-o em sua conhecida trilogia do "gaúcho a pé", em que a crise econômica levará o mundo pastoril ao êxodo para as periferias da cidade. Por fim, Aureliano de Figueiredo Pinto e Dyonélio Machado são autores que buscam retratar o insucesso do processo de modernização em incorporar os habitantes das áreas rurais.
\end{abstract}

PALAVRAS-CHAVE: literatura de viagem; literatura sul-rio-grandense; dispositivo; gaúcho a pé.

ABSTRACT: The literature of Rio Grande do Sul has works in which the journey and the process of displacement are mobilizers to the narrative. In the beginning, the author's desire to portray "local color" approached regional fiction to picturesque portraits of regionalism. This romantic tradition will be undermined by the Naturalism of Alcides Maya's work, which shows a dying South. Cyro Martins will continue this ongoing process by describing in his trilogy of "gaúcho a pe" (gaucho on foot) the economic crisis that leads the pastoral world to an exodus, ending in misery on peripheries of cities. Finally, we have, in Aureliano de Figueiredo Pinto and Dyonélio Machado, authors who seek to portray the failure of the modernization process incorporating the inhabitants of rural areas.

KEYWORDS: travel literature; Southern Brazilian literature; dispositive; gaucho on foot.

\section{Apresentação}

Estado marcado pela localização geográfica no limite sul das fronteiras do país, cuja identidade peculiar possui muitas semelhanças com os países vizinhos, não é de se estranhar que a literatura no Rio Grande do Sul tenha em seu corpus diversos livros cujo enredo se desenvolva ao redor de viagens e deslocamentos territoriais. Logo, no desejo de uma maior compreensão da territorialidade dessa região, seria interessante tematizar como os diversos meios de transporte foram determinando a tessitura das narrativas da localidade.

Podemos começar nossa caminhada pela sugestão de que, numa região onde a proximidade com a vida no campo é determinante, os meios de transporte influenciam de alguma maneira a identidade dos sujeitos. Na região, esse enquadramento alinharia lado a lado centauros e motoristas, vaqueanos e pedestres, e indicaria um quadro interessante do tema que pretendemos tratar. Para isso, um bom ponto de partida teórico seria pensar o meio de transporte como um "dispositivo" determinante das subjetividades da região.

\footnotetext{
* Mestre em Teoria, Crítica e Comparatismo pela UFRGS. Mestrando em Literatura, História e Memória pela PUCRS, onde é bolsista CNPq. Contato: jkdornelles@ hotmail.com
} 
Giorgio Agamben considera como "dispositivo" tudo aquilo que possui a capacidade de "capturar, orientar, determinar, interceptar, modelar, controlar e assegurar os gestos, as condutas, as opiniões e os discursos dos seres viventes" (AGAMBEN, 2005 , p. 12). O conceito de dispositivo visa dar conta de um operador que funciona como uma rede de sentidos, relacionando-se tanto com o poder econômico quanto com os processos de subjetivação discursivos. Aquilo que passa pelos ritos, pelas regras de conduta e pelas instituições de um coletivo e que dispõe o mundo material de determinada maneira, sendo interiorizado num sistema de crenças, sentimentos e gestos. Um exemplo nesse sentido seriam as vestes tradicionais do gaúcho, um dispositivo no qual se encontram seus hábitos e comportamentos, evidenciando, por essa via, os trabalhos de domar o cavalo, laçar, carnear o gado etc.

Comecemos delimitando um enfoque específico de análise, deixando de lado cronistas ou documentação histórica, e selecionando apenas material representativo na ficção. Pensar a literatura de viagens no Rio Grande do Sul passaria necessariamente por alguns registros inaugurais, como os relatos de Viagens ao Rio Grande do Sul, de Auguste Saint Hillaire, escrito entre 1820 e 1821; a Viagem militar ao Rio Grande do Sul, registro escrito no ano de 1865 por Conde d'Eu; ou ainda as fontes primárias reunidas por Guilhermino César em Primeiros cronistas do Rio Grande do Sul, que vão de 1605 a 1801. Alguns dos relatos de viajantes reunidos nessa última obra, que contêm material de quase dois séculos, guardam exemplos das curiosidades geográficas e do pitoresco dos costumes, que seriam preciosos para a compreensão sobre viagens e deslocamentos dentro do território do Rio Grande do Sul.

Mas nosso enfoque se decide pela ficção, espaço privilegiado na construção do valor simbólico da cultura. Possuindo um importante aspecto de subjetivação, a literatura pode revelar aspectos inusitados dos dispositivos em operação. Organizamos o texto em três momentos, que buscam acompanhar a forma em que foram representados os cenários e os viajantes típicos dessa região. Devido ao curto espaço de um artigo, nosso percurso se inicia no século XIX, com as representações próximas ao romantismo, e fixa um ponto de chegada na ficção de Dyonélio Machado, em que o carro e a cidade assumirão um papel de destaque. Haveria ainda uma ligação entre a ficção do autor e esses temas: na maneira como os personagens de Desolação tratam seus carros, por exemplo, seria possível ver muito do cuidado que criadores de cavalos teriam com seus animais.

Num primeiro momento, predominam o cavalo e a figura do "centauro dos pampas". Com o advento da industrialização, passamos à decadência desse meio de transporte típico, o que dará margem à ficção do "gaúcho a pé". E, por fim, temos a democratização dos meios de acesso, e o sul-rio-grandense passa a andar de carro, trem, navio e avião. A ficção então nos dará testemunho de uma nova obstrução ao acesso das massas a esses meios, graças ao malogro das esperanças de industrialização e ao crescimento da pobreza. De centauros dos pampas a motoristas de calhambeques, de vaqueanos a "gaúchos a pé", os viajantes do sul se veem, assim, às voltas com o drama da possibilidade ou não de acesso aos seus meios de transporte.

\section{Primeiro tempo: o mito do centauro dos pampas}

Considerado cronologicamente o segundo romance da literatura brasileira e o primeiro do regionalismo, A divina pastora, escrito por José Antônio de Caldre e Fião, 
inaugura uma série de temáticas que serão reiteradas posteriormente. Publicado pela primeira vez em 1847, época do Brasil Império, o romance narra, em um estilo folhetinesco, as paixões da virtuosa Edélia pelo bravo Almênio, personagens atormentados pelo impiedoso vilão Francisco. Apresentando uma região ainda desconhecida para a maioria da corte brasileira, a obra adotará como cenário as paisagens e os costumes locais, fazendo eco ao anseio típico de autores românticos que buscavam registrar a "cor local" àquela época.

Nessa obra, visitaremos a nascente vila de São Leopoldo e uma Porto Alegre que ainda não tem oitenta anos, passando por Viamão, para cruzar o Passo da Cavalhada rumo ao Belém Velho. Era 1845, e a capital do Estado do Rio Grande do Sul ganhava novas ruas, que surgiam batizadas com apelidos carinhosos: a Rua da Praia, que levava às margens do Guaíba; a Praça do Paraíso, que se tornaria o Largo do Mercado Público; a Rua da Bragança, de onde despontava a "Caridade", futuro Hospital da Santa Casa.

O panorama descrito pelo autor é rico em detalhes, que fazem um retrato quase fotográfico ao apresentar uma cidade ainda então desconhecida pela corte carioca. A viagem a cavalo feita por Almênio até o Vale dos Sinos, descrevendo as comunidades de imigrantes alemães que ali se instalavam, é uma curiosa máquina do tempo para quem se aventura pelas páginas dessa obra, que até poucos anos atrás era dada como perdida. Dentre os pequenos relatos do livro, há um caso que merece destaque: o menino campeiro punido por um imigrante. Invadindo campo alheio para buscar seu gado perdido, o garoto retém o costume dos sul-rio-grandenses ainda habituados a uma terra sem cercas. $\mathrm{O}$ relato refere que, por conta do imigrante desconhecer os hábitos da região e, portanto, passar um castigo demasiado cruel por algo que não era bem um crime, o menino se faria adulto e voltaria em busca de vingança. Aí teremos a descrição embrionária do típico cavaleiro gaúcho, um "monarca das coxilhas": o senso de honra e a audácia, os trajes típicos e os costumes do churrasco e do chimarrão. No entanto, não se usa ainda o termo gaúcho para definir essa figura.

Será em sua obra seguinte, $O$ corsário, publicada pela primeira vez em 1849, que Caldre e Fião descreverá com maior precisão as figuras que se tornarão típicas do Rio Grande do Sul. A obra será publicada apenas quatro anos após o fim da Revolução Farroupilha, sendo a disputa aproveitada como material dentro do texto. O cavalo aqui é um dispositivo-chave do dinamismo da narrativa. Acompanhando os movimentos dos milicianos em suas contendas e choques de guerrilha, o autor descreverá os cenários decisivos dessa disputa, como a fuga de Camaquã por Bento Gonçalves e a fuga do governador do Estado (à época, "presidente" da província) rumo ao Rio Grande, à localidade de Pedras Brancas, onde se reuniam os rebeldes farroupilhas. Entre as figuras heroicas dos militares, há uma série de sujeitos menores: contrabandistas, aventureiros e o corsário italiano que dá título ao livro.

O corsário italiano aparece em cena entre as praias de uma Tramandaí ainda distante da urbanização do século XX. As dunas, as aves e os pescadores rústicos isolados do mundo compõem uma paisagem plena de pitoresco, na qual o autor vai cevando sua narrativa. É por dentro desses "quadros naturais" (os capítulos do livro são chamados de "quadros") que vemos surgir a figura típica do sul-rio-grandense: quatro moços vestidos "à gaúcha”. A cavalo e de indumentária completa: chapéu de abas largas, poncho, guaiaca e botas com pesadas chilenas de prata; armados com facas, laço e boleadeiras e apresentando aspecto de uma lhana franqueza e alegria pronunciada. Seu diálogo é recheado de expressões do dialeto regional, o que põe em cena a linguagem da "cor local". 
Caldre e Fião foi talvez um dos primeiros autores a registrar o uso de "gaúcho" em seu valor positivo, uma espécie de sinônimo de campeador - diferente do significado pejorativo que em geral se atribuía ao termo àquela época, algo próximo a bandido, como indica Reverbel (2002). Em certo momento, surge a descrição de um bravo e guapo gaúcho que serviria como emissário de confiança para investigar intrigas na região. É a descrição da figura do "vaqueano", que manobra a logística dos cavalos e geografias e é, por vezes, comparável à figura do "centauro dos pampas" da gauchesca, mais tarde explorada por Apolinário Porto Alegre e Simões Lopes Neto.

Nas obras desses autores, teremos uma elaboração mais precisa da figura mítica do regionalismo, o gaúcho, que sobre seu cavalo desbrava um horizonte infinito e conhece até as pequenas pedrinhas de cada estrada e região.

O gaúcho é personagem característica da cultura sul-rio-grandense, que, quando pode, se faz representar por ele. Essa identificação remonta à época da Revolução Farroupilha, como mostra o cancioneiro popular recolhido por Apolinário Porto Alegre. E, após ter sido elevado a herói por José de Alencar, em $O$ gaúcho, tornou-se presença assídua nas obras dos românticos sulinos, que o mitificaram em novelas e poemas. (ZILBERMAN, 1992, p. 15).

É com essas configurações literárias mais bem-sucedidas que se fixa o mito do "gaúcho a cavalo" como o sujeito que domina a geografia do pampa e se identifica com a figura mitológica do centauro. Segundo Flávio Loureiro Chaves, o regionalismo no Rio Grande do Sul se formou a partir da inspiração romântica e "dessa intenção programática de documentar o espaço circundante através de cenários típicos, da recuperação do acervo folclórico e lendário, da inclusão dos falares regionais na matéria de ficção" (CHAVES, 1982, p. 12).

Haveria, portanto, o desenvolvimento de um modelo ficcional que vai de Caldre e Fião até Simões Lopes Neto, em que o desejo de descrever a "cor local" da região com fidelidade se aproveita da linguagem coloquial e do pitoresco dos costumes, ao ponto de mitificar seus habitantes (os "centauros" do pampa). "Tudo concorre para a ideia 'regionalista' duma raça viril e perfeitíssima, a raça gaúcha enfim, suficiente a si mesma no contraste com o elemento externo" (CHAVES, 1982, p. 12).

Como a citação indica, um dos primeiros a retratar o mito foi o escritor cearense José de Alencar. Sua obra $O$ gaúcho, publicada pela primeira vez em 1870, retrata a "cor local" dos pampas e a paisagem solene e melancólica onde cavalgam a toda brida homens austeros e orgulhosos. Sobram momentos referenciais nos quais as vastas campinas, que se desdobram pelas abas da coxilha, são "como as páginas de um capítulo do Brasil": "O dorso da coxilha é o lombo do livro (...) que recordações heroicas não despertam os nomes de São Borja, Ibicuí, Rosário, Corumbá, Índia-morta, São Carlos, Catalã, Taquarembó e Paissandu!” (ALENCAR, 1978, p. 86).

Sabe-se que algumas inadequações da obra de Alencar despertaram em Apolinário Porto Alegre o desejo de responder pela via da ficção, numa obra que resguardaria, por meio do testemunho - que Alencar não tinha-, a realidade gaúcha. A começar pelo adjetivo "gaúcho", que, à época de Apolinário, ainda não havia se estabelecido positivamente como hoje. Por isso, chamará seu protagonista, título do livro publicado em 1872 , de $O$ vaqueano.

Era uma natureza admirável, não tanto pelas amplas manifestações de músculos de ferro, como pela perícia e inteligência com que guiava os exércitos da República, e a lhaneza e bondade de caráter. Também jamais 
houvera rio-grandense que, como ele, conhecesse a província. Não lhe escapava uma jeira de terra, ainda mesmo perdida nos ínvios sertões ou em banhados de largo perímetro. Tinha a memória fiel até para as nugas locais. Era uma verdadeira vocação. (...) constituía de per se o mais exato arquivo topográfico, um mapa vivo e pitoresco. (PORTO ALEGRE, 1987, p. 29-30).

O vaqueano de Apolinário é este homem que cruza as distâncias a cavalo, guiando as tropas republicanas com conhecimento preciso. Suas viagens atravessam o estado, dos campos de Vacaria ao norte do rio Pelotas, do sul de Taquari ao lombo verde-negro da Serra Geral: "nos mistérios campeiros ninguém o excedia. Iguais os encontrava, melhores nunca". (PORTO ALEGRE, 1987, p. 30). Além da mudança do termo "gaúcho" para "vaqueano", há também outra modificação. Enquanto a personagem de José de Alencar se deixava levar de maneira exaltada e inconsciente pelas paixões da política, o "vaqueano" de Porto Alegre já compreendia como se dividiam as disputas partidárias, posicionando-se politicamente com mais informação.

Proclamada a República, e adentrando o século XX, permanecerão na literatura sul-rio-grandense algumas de suas representações regionais míticas. A economia se modifica, mas ainda idealizam-se os horizontes e o sem-limite dos deslocamentos: um vaqueano a cavalo também será a figura típica eleita por Simões Lopes Neto. A personagem Blau Nunes viaja por geografias e memórias, contando casos enquanto constrói seus quadros da vida sulista. O início de seu relato dá conta de seus deslocamentos: do litoral às coxilhas, do rio Uruguai à Lagoa Mirim, das penedias do Caverá às planícies do Saicã, Santa Tecla, São Gabriel, Santa Maria, Passo Fundo, Lagoa Vermelha, Soledade, Ibicuí. Para cada um dos lugares, Blau tem uma recomendação turística: as águas, o mel, as estâncias, os pomares, as plantações. Contos como "Boi velho" e "No manantial" são como viagens ao registro pitoresco da "cor local" regionalista. E a mitificação do gaúcho em Simões Lopes é evidente: sempre moreno, forte, franco e leal, em oposição aos forasteiros, que são louros, covardes e desonestos. Blau é descrito como tipo genuíno do rio-grandense, o "monarca das coxilhas" que percorre as distâncias a cavalo e reúne os atributos heroicos do mito tradicionalista.

\section{Segundo tempo: de vaqueanos a migrantes}

Com a proclamação da República ocorrendo próxima ao fim do século XIX e o processo de modernização que começava a chegar ao estado, o substrato histórico do qual emergiam os mitos regionalistas foi pouco a pouco sendo ameaçado de extinção. A vida pastoril foi sofrendo interferências tecnológicas, as grandes propriedades passando cada vez mais a serem divididas em pequenas propriedades familiares. A isso se somam fatores como a imigração, e o fim das contínuas guerras nas quais o estado se via envolvido. Serão diversas as modificações que abalam o cenário e os costumes do Rio Grande do Sul.

Esse processo de modernização do campo, que modifica a economia rural e seus meios de transporte, o campesinato e as paisagens rurais, acontece tardiamente no Rio Grande do Sul se o compararmos com outras regionalidades. Williams (1990, p. 12), referindo-se às modificações da região agrária na Inglaterra entre 1760 e 1840, afirma: "A Revolução Industrial não transformou só a cidade e o campo: ela baseou-se num 
capitalismo agrário altamente desenvolvido, tendo ocorrido muito cedo $\mathrm{o}$ desaparecimento do campesinato tradicional".

Será o avanço do processo de industrialização no Rio Grande do Sul que irá reconfigurar a economia da região, modificando a vida nos campos, apartando-a com cercas, pavimentações, logísticas. Temos assim toda uma nova topografia da vida rural e novos meios de locomoção. Essas modificações produzirão uma série de respostas ficcionais, que se alternam primeiro entre posições nostálgicas e desiludidas, passando no romance dos anos 1930 a diagnóstico investigativo da economia da região.

Como afirma Zilberman (1992, p. 15),

[a] desmitificação, contudo, não tardou, resultante, de certa maneira, das mudanças na estrutura tradicional da economia rio-grandense, associada à pecuária e à vida no campo. A transformação, originalmente vista como decadência pelos grupos conservadores, tom que se transferiu à literatura de tendência regionalista. Ela transparece, no início do século, nas obras de Alcides Maya, João Simões de Lopes Neto, Amaro Juvenal, um pouco mais tarde Darcy Azambuja, que constatam com perplexidade, frequentemente com desgosto, a nova situação. A ficção aparecida nos anos 30 assume, todavia, outra postura, procurando diagnosticar a natureza do fenômeno e suas causas.

É com Alcides Maya que a marca da decadência regional primeiro se faz representada em um nível mais profundo. Suas obras ainda resguardam o mesmo desejo de fotografar os cenários típicos e pitorescos da região. Publicada pela primeira vez em 1911, sua obra Tapera, por exemplo, leva o subtítulo de "cenários gaúchos". Mas esses retratos atestarão as mutações que sofriam a economia agrária da região e as subjetividades de seus habitantes.

Nas obras do autor, há uma profusão de símbolos de decadência. Ruínas vivas por exemplo, são tanto as lendárias figuras típicas, os "monarcas das coxilhas" que já não detêm nenhuma monarquia, quanto a própria terra, que se multiplica em taperas, águas paradas, ecos mortos, "longínquos rumores dispersos, quebrados, do pampa", como em citação de Alma Bárbara (MAYA, 1991, p. 46). A cena final de Ruínas Vivas, quando o protagonista está para abandonar os pagos onde vivia, desiludido por já não encontrar mais honra naquela terra, é significativa: "Odiava-a; supunha eterna em sua força e retirou-se ameaçando de punhos crispados, sem saber que lá, como em tudo ao redor, como nele próprio, só havia restos - de velhas crenças, de velhas construções, de velhas raças..." (MAYA, 1910, p. 235).

Já em seu livro de contos Tapera, até as árvores parecem acenar um adeus triste aos fantasmas da memória de um passado que desvanece (MAYA, 2002). O próprio cenário do campo parece definhar entre ruínas e nostalgias do passado. É pela adoção deste registro do depauperamento da vida no campo que Cyro Martins (leitor de Alcides Maya desde jovem) desenvolverá sua conhecida "trilogia do gaúcho a pé". Nela, o depauperamento da região estará em vias de desenvolvimento ainda mais avançado, e é nela que observaremos uma nova etapa relativa aos meios de transporte.

Se nas representações românticas o modelo do viajante é o "centauro dos pampas", aquele que se sente dono da imensidão do horizonte e que percorre a cavalo imensas regiões da América Latina, Cyro Martins mostrará, ao contrário, a progressiva imobilização dos gaúchos. A cena inicial de Sem rumo é sintomática do movimento declinante que se opera em toda sua trilogia: o livro se inicia com a descrição do menino Chiru arranjando e equipando seu burrinho, que passa, por sua vez, a mover um moinho 
num movimento circular e sem destino, em que só avança o buraco de barro sob seus passos.

Será esse sem rumo que marcará as viagens dos personagens da trilogia de Cyro Martins, os quais darão com a cara numa "porteira fechada" — para aproveitar o título de outro de seus livros. Na obra com esse nome, a personagem João Guedes é expulso do campo para acabar na periferia de sua cidade, onde terminará sendo preso por roubar ovelhas. Uma de suas últimas tentativas de sobrevivência é vender seu cavalo para conseguir dinheiro, acabando, assim, na figura do "gaúcho a pé". Como afirma Lara (1985, p. 59), "o mito do gaúcho não pode se manter sem a existência do cavalo. O gaúcho a cavalo tem a estância, a distância, o trabalho, o lar - todos sustentáculos do mito. A cavalo, o gaúcho tem uma finalidade, a pé cai toda uma concepção de vida; sem cavalo ele não é ninguém".

Por vezes, é também a própria paisagem que deve desvanecer, como em Estrada nova, quando a morte de um umbu é o derradeiro golpe no estancieiro Teodoro. "Toda a manhã Teodoro passou sorumbático, pesadão, cismando mais desgraças. Tudo por conta da morte do umbu? Quase tudo" (MARTINS, 2008, p. 189). A relação entre paisagem e personagem é tão estreita que a morte da árvore simbolizará a morte da personagem, que, assim como os pobres peões, acaba também tendo que abandonar o campo.

Se por um lado a vida no campo vai se tornando adversa para a grande maioria de seus habitantes, desadaptados ao avanço de uma modernização que excluirá do desenvolvimento econômico grandes parcelas das classes médias e dos estancieiros, por outro lado a cidade também se apresenta como um lugar ameaçador. "Indo para a cidade, porém, morreriam em seguida. Todos dizem que na cidade se morre em seguida. Que pena, ela queria morrer naquele rancho, ainda que fosse agora!" (MARTINS, 2008, p. 149).

Temos, também, em alguns momentos dessa trilogia de Cyro Martins, o aparecimento do automóvel. Ele é utilizado como meio de transporte principalmente por representantes da classe média e da elite. Alguns dos motoristas que temos em Porteira Fechada são o filho de estancieiro, Hélio Bica, e Dr. Orlando, que utiliza o carro como meio de locomoção rápida para atendimentos na região.

Essa modernização dos meios de transporte voltará nas obras que veremos a seguir. A chegada dos antes "virtuoses" do meio de transporte animal à condição de pedestre é característica marcante que podemos guardar desse momento. Além disso, no caminho para o (sem) destino das periferias da cidade, são as carroças e os burros de carga que servem de derradeiro meio de transporte aos gaúchos que ficarão a pé e sem muitos horizontes a acessar. A trilogia de Cyro Martins, desenvolvendo alguns dos temas de Alcides Maya, pode representar, então, as dificuldades de adequação dos habitantes regionais à reconfiguração da paisagem do campo na modernidade.

\section{Terceiro tempo: passageiros, motoristas e pedestres}

Como vimos, num primeiro momento tínhamos os míticos viajantes sem limites, donos dos horizontes e conhecedores das trilhas. A modernização traz a segregação, o desajuste, impõe limites e fronteiras e rouba o cavalo dos "centauros", que se encontram desnutridos, desonrados e inaptos para o trabalho no campo. Restam as carroças para o transporte dos poucos pertences rumo a uma cidade que não lhes destina um futuro melhor. Essa modernização malograda da afirmação da identidade regional terá em 
Memórias do Coronel Falcão, obra escrita entre 1936 e 1937 por Aureliano de Figueiredo Pinto, um retrato único, posto que representa a decadência da elite, e não das classes baixas.

Decidido a tornar-se representante político de sua região, o estanceiro, por meio de sua experiência fracassada, mostra o outro lado da moeda do desenvolvimento regional. Se em Cyro Martins temos o fracasso das classes populares, Aureliano mostra como fracassava também o melhor das elites, que não se adequaram à economia dos novos tempos. Enganado pelo poder urbano e consumindo suas riquezas no desejo de defender os interesses de sua região, o Coronel Falcão acaba tragicamente ridicularizado, tanto em seu sonho privado de casamento quanto de realização na vida pública da política.

É interessante que o meio de transporte que leva a personagem à sua perdição na "cidade-prisão", como será chamada, será o trem. A viagem da comitiva de partidários de Falcão ao encontro das repartições, cafés, bancos e quartéis que conhecerão representa algumas das páginas mais memoráveis do livro:

Vamos fazer alguma coisa pelos pagos. Hospital. Agronomia. Veterinária. Dispensário. Colônias-modelo. Valorizar o nacional. Mas para isto, era necessário deixar a rude Esparta pastoril de rodeios e madrugadas. Aprender a dialética dos sofistas. E descer à Ágora do vilarejo... (PINTO, 1986, p. 47).

Já não é a cavalo, mas no percurso do vagão-locomotiva que os patrícios do estado agora vão conhecendo sua região. Em cada parada, a comitiva encontra algum assunto, uma figura, uma anedota. Cacequi, Santa Maria, Jacuí, Cachoeira do Sul, Guaíba... Da fronteira à capital, a viagem que Coronel Falcão faz ao encontro de sua derrocada é, afinal, a viagem da modernidade malograda, que leva os patrícios regionais, os estancieiros, ao seu encontro com a esfinge multifacetada na cidade globalizada. Será também dessa crise da modernização periférica (CEVASCO, 2014) que outro autor irá narrar viagens regionais. Dyonélio Machado irá incorporar elementos da modernidade em suas narrativas, ao mesmo tempo em que revela uma preocupação crítica com as camadas populares, como em Cyro Martins.

Já em sua primeira obra de ficção, os contos de Um pobre homem, Dyonélio Machado oferecerá algumas representações interessantes da modernidade regional. No conto "Melancolia", teremos a figura de um manobrista de locomotivas introspectivo, ingênuo e tido como um idiota. Esse protagonista, chamado Ângelo, cuida das máquinas com a atenção que se destina a bichos de estimação. Em certo momento, ao perceber que sua locomotiva manobreira, por ser pesada demais, não poderia voltar para a garagem caso saísse do pátio da estação onde funcionava, a personagem percebe que ele também era "como uma máquina": como a locomotiva, todos os seus caminhos eram sem retorno, já que ele jamais voltaria dos exílios que o destino porventura lhe reservasse. E assim, a partir do dia que a "manobreira" é levada para longe, seus vizinhos, colegas, ninguém nunca mais the viu... "Nunca mais! A 'porta', meus amiguinhos, aquela garganta impassível que se abria para o mundo, tragara-o para todo o sempre..." (MACHADO, 2017, p. 77).

Também no conto homônimo ao livro, "Um pobre homem", a crise na vida no campo frente à crescente industrialização é narrada em toda sua pungência. Buscando modernizar sua lavoura, o protagonista, viúvo e pai de uma filha que voltaria para casa depois de se desencaminhar sem conseguir casamento, decide pegar um empréstimo e comprar um trator para arar o campo, modernizando sua pequena terra. Na obsessão 
pelo sucesso de seu projeto, acaba descuidando de sua filha, que adoece e morre de uma doença no pulmão. O pai, no entanto, só lamentará a ausência da filha quando finalmente der suas reformas na fazenda por concluídas.

A modernização de Porto Alegre, com os bondes, as repartições burocráticas e as vitrines com produtos, aparecerá com força única em sua obra seguinte, Os ratos. Na viagem até o centro da cidade, todo um horizonte de progresso se revela e se afasta de Naziazeno, que se vê incapaz de solucionar a problemática ínfima, e no entanto vital, a qual enfrenta.

Se por um lado temos o mundo urbano no processo de industrialização que se estabelecia com Getúlio Vargas chegando ao poder, por outro, a periferia de onde Naziazeno surge jamais encontra realização nas áreas centrais de desenvolvimento. A obra dá poucos indícios do passado do protagonista, mas, em um trecho mais direto, revela-se um passado bom, no qual grupos de crianças podiam andar livres pela rua, e havia aconchego e calor humano. Sua mãe o chama e lhe oferece leite, justamente o leite que ele procura pagar, uma bebida que havia em abundância em sua infância. Essa memória sugere um passado em uma cidade do interior, onde havia vacas por perto, mas poderia ser também o próprio subúrbio da capital, que à época ainda guardava características rurais.

Podemos relacionar os personagens de Dyonélio com os da obra de outros escritores gaúchos com quem ele simpatizava. Por exemplo, o Miguelito, de Ruínas vivas, que ao final da obra abandona seu pampa rumo a um lugar outro, cheio de raiva e desilusão. Ou Chiru, de Sem rumo, que sai do campo e acaba na periferia da cidade. Os ratos, no entanto, revela uma falta de destino, já na cidade, para as camadas que viviam à margem. As obras seguintes de Dyonélio incorporarão ainda descrições de cenários da modernidade, o registro de quadros típicos do campo em meio a viagens e discutirão o acesso dos habitantes aos meios de transportes.

Em suas três obras seguintes, a problemática do deslocamento das camadas populares na modernidade vai se revelando com destaque. O Louco do Cati, publicado pela primeira vez em 1942, apresenta uma diversidade de meios de locomoção: um bonde, um automóvel, a diligência das memórias, o ônibus, o navio, o caminhão, o trem, o avião. Em Desolação, de 1944, o foco nos cuidados ao automóvel, que se intensifica e domina os afazeres dos personagens, chega ao esgotamento e à impotência frente à incapacidade de deslocamento. O mesmo tema que se desenvolve ao longo desse livro dominará o seguinte: Passos perdidos, de 1946. É como se Dyonélio tivesse motorizado os gaúchos sem cavalo para, ao final, revelar que, ainda assim, eles acabariam deslocados e a pé de novo.

Na primeira dessas obras, O Louco do Cati, o movimento de fuga e retorno é parte importante do núcleo narrativo. Seu protagonista é levado de situação em situação, só reagindo para fugir dos espectros de seu passado. Não sabemos se é o Estado de exceção imposto por Getúlio Vargas o que desperta as memórias do Cati ou se ele já vivia fugindo antes disto. O fato é que, ao longo de seu deslocamento, teremos o desfile de cenários e costumes da época, por meio dos quais o autor apresenta aquele mundo tanto para o Louco quanto para o leitor.

Decidi porém fazer, quanto à forma, um romance-revista. (...) Vamos ver como é que o Aurélio Buarque de Holanda Ferreira define o romance-revista nesse seu Novo Dicionário da Língua Portuguesa: "Peça de teatro, com quadros de música e dança, com anedotas, alegorias, sketches, etc., na qual se criticam os fatos mais em evidência da época”. (MACHADO, 1995, p. 30). 
Dyonélio teria adotado uma forma heterogênea com o objetivo de retratar os fatos mais em evidência à época. Sua obra seria também uma série de quadros, fotografias, do pitoresco regional e nacional. Talvez por isso o livro gere tanto estranhamento ao leitor desavisado: fatos aparentemente desconexos se ligam uns aos outros, muitas vezes por analogia e com poucas sugestões sobre como deveríamos relacionar essas partes. É por uma estranha afinidade que esses fatos se conjugam em um significado. Diversas cenas e cenários passam diante dos olhos do leitor, e uma leitura rápida muitas vezes deixa escapar estas possíveis correlações.

Temos, assim, a exposição do pitoresco da época: a estrada para Tramandaí, construída havia apenas alguns anos, o cemitério de navios nas praias do litoral gaúcho, o farol de Solidão, a pesca, o funcionamento dos presídios e os costumes do Rio de Janeiro, a capital do país à época, a rotina dos passageiros a bordo de um navio de primeira classe, o funcionamento das repartições etc. É com essas sugestões que Dyonélio vai elaborando a "cor local", fugaz como a modernidade que ia perdendo sua aura em meio à massificação industrial.

Já em Desolação, o carro é incorporado como elemento central da viagem dos personagens. Parte substancial da narrativa é ocupada com o relato dos reparos do calhambeque Borboleta e com seu deslocamento pelo interior do estado. Para Barbosa e Grawunder (1995), é curioso que os cuidados com o carro se assemelham aos cuidados com um animal de estimação (passam a mão no carro, dão de beber gasolina a ele etc.). É como se o grupo de mecânicos da narrativa fossem os velhos centauros do pampa, amigos íntimos de seus cavalos. Dyonélio moderniza os gaúchos a pé, dando-lhes o automóvel como meio de transporte que substitui os cavalos perdidos. Mas só para deixá-los sem meios de transporte de novo.

Se podemos dizer que nessas três obras o tema do deslocamento ocupa parte central, é justamente porque em Passos perdidos a incapacidade de viajar se torna o próprio tema da narrativa. Já no título (que ecoa o Sem rumo, de Cyro Martins) o esgotamento das alternativas é representado tanto pela ausência de destino quanto pela ausência de um meio de locomoção que permita ao personagem chegar até ele. $\mathrm{O}$ protagonista pega ônibus, consegue caronas em caminhões, mas, na maior parte do tempo, conta somente com o próprio corpo. E, dado que está empobrecido, também já não pode ir a lugar nenhum. Portanto, em certo sentido, as obras de Dyonélio Machado aqui analisadas parecem retratar um gaúcho a pé... de novo.

Temos, então, quase como a conclusão lógica de um longo processo de documentação das condições de locomoção dos habitantes do interior do estado: de centauros a vaqueanos e então viandantes, num processo de modernização que impôs fronteiras e limites a uma região onde antes se viajava livremente. Depois, com o avanço de uma modernidade periférica, obtém-se o automóvel; com ele, também surge o motorista, que logo se tornará pedestre (ou "caroneiro"), num processo que acabará mostrando seus limites e deixando o "gaúcho a pé" mais uma vez.

Podemos reconhecer, assim, por meio das diversas modificações de acesso e da relação com os meios de transporte, como se modificam as identidades e algumas das práticas históricas da região. Da "cor local" dos primeiros autores aos diagnósticos ficcionais de Cyro Martins e Dyonélio Machado, tentamos indicar parte dessa rede de sentidos que aqui opera. Buscamos sugerir um conjunto de aspectos que poderiam ser mais amplamente desenvolvidos com a incorporação de aspectos sociológicos ou 
psicanalíticos, por exemplo, caso se desejasse ampliar o mapa teórico e circular por novas órbitas ao redor desses instigantes dispositivos de viagem.

\section{REFERÊNCIAS}

ALENCAR, José de. O Gaúcho. São Paulo: Ática, 1978.

AGAMBEN, Giorgio. O que é um dispositivo?. Outra travessia. Florianópolis, v. 5, 2005, p. 9-16.

BARBOSA, Márcia Helena Saldanha; GRAWUNDER, Maria Zenilda (Orgs.). Dyonelio Machado. Porto Alegre: Unidade Editorial Porto Alegre, 1995.

CÉSAR, Guilhermino. Primeiros cronistas do Rio Grande do Sul. Porto Alegre: EDURGS, 1981.

CEVASCO, Maria Elisa. Modernização à brasileira. Revista do Instituto de Estudos Brasileiros, São Paulo, n. 59, p. 191-212, dez. 2014.

CHAVES, Flávio Loureiro. Simões Lopes Neto: Regionalismo \& Literatura. Porto Alegre: Mercado Aberto, 1982.

FIÃO, José Antônio do Vale Caldre. O corsário. Porto Alegre: Movimento, 1979. A divina pastora. Porto Alegre: RBS, 1992.

EU, Luís Filipe Maria Fernando Gastão d'Orleans, Conde D'. Viagem militar ao Rio Grande do Sul. São Paulo: EDUSP, 1981.

LARA, Elizabeth Rizzato. O gaúcho a pé. Porto Alegre: Movimento, 1985.

LOPES NETO, João Simões. Contos gauchescos \& Lendas do sul. Porto Alegre: L\&PM, 2012.

MACHADO, Dyonélio. Passos perdidos. São Paulo: Editora Moderna, 1982.

. O cheiro de coisa viva. Rio de Janeiro: Graphia Editorial, 1995. . O Louco do Cati. São Paulo: Planeta do Brasil, 2003. . Os ratos. São Paulo: Planeta do Brasil, 2004. . Desolação. São Paulo: Editora Planeta do Brasil, 2005. . Um pobre homem. Brasília: Siglaviva, 2017.

MARTINS, Cyro. Porteira fechada. Porto Alegre: Movimento, 2001. 
Estrada nova. Porto Alegre: Território das Artes/CORAG, 2008. . Sem rumo. Porto Alegre: Território das Artes/CORAG, 2008.

MAYA, Alcides. Ruínas vivas. Porto Alegre: Lello Irmão, 1910. Alma bárbara. Porto Alegre: Movimento, 1991. Tapera. Porto Alegre: Movimento, 2002.

PINTO, Aureliano de Figueiredo. Memórias do Coronel Falcão. Porto Alegre: Movimento, 1986.

PORTO ALEGRE, Apolinário. O Vaqueano. Porto Alegre: Movimento, 1987.

REVERBEL, Carlos. O gaúcho. Porto Alegre, L\&PM, 2002.

SAINT-HILAIRE, Auguste de. Viagem pelo Rio Grande do Sul. Porto Alegre: Martins Livreiro, 2002.

WILLIAMS, Raymond. O campo e a cidade. São Paulo: Schwarcz, 1990.

ZILBERMAN, Regina. Roteiro de uma literatura singular. Porto Alegre: Universidade/UFRGS, 1992. 